\title{
Práticas Culturais e Ciberculturais: para pensar a relação com as tecnologias
}

\section{Nilda Aparecida Jacks, Mariângela Machado Toaldo e Erika Oikawa}

\section{Resumo}

A proposta deste texto é expandir a reflexão sobre práticas culturais e sua importância para analisar os modos de fazer e agir no contexto digital, com seus processos e ações convergentes, em fluxo e em tempo real. Primeiramente, recuperam-se as definições de prática em seu sentido mais genérico, com 0 intuito de assentar as bases para 0 entendimento do que sejam práticas culturais, partindo-se dos diferentes significados atribuídos por autores como Pierre Bourdieu, Michel De Certeau, Teixeira Coelho e Eric Maigret. Em um segundo momento, volta-se para o contexto e as características da cibercultura, os processos de consumo nela existentes e as práticas deles resultantes, a partir das possibilidades que as tecnologias digitais e a internet oferecem.

Palavras-Chave

Práticas culturais 1. Tecnologias 2. Cibercultura 3.

Nilda Aparecida Jacks | jacks@ufrgs.br Professora do Programa de Pós-Graduação em Comunicação e Informação da Universidade Federal do Rio Grande do Sul - UFRGS, Brasil. Pesquisadora nível 1 do CNPQ.

\section{Mariângela Machado Toaldo}

I mariangela.toaldo@ufrgs.br

Professora da Faculdade de Biblioteconomia e Comunicação da Universidade Federal do Rio Grande do Sul - UFRGS, Brasil. Doutora em Comunicação Social pela Pontifícia Universidade Católica do Rio Grande do Sul - PUCRS, Brasil.

\section{Erika Oikawa | erikaoikawa@gmail.com}

Doutoranda do Programa de Pós-Graduação em Comunicação Social da Pontifícia Universidade Católica do Rio Grande do Sul - PUCRS. Bolsista CAPES/FAPERGS.

\section{Introdução: 0 que são práticas?}

André Comte-Sponville, em seu Dicionário

Filosófico, faz constar dois verbetes

relacionados ao assunto: prática e práxis.

Prática (pratique) é descrita como

[...] uma atividade (praxis em grego ou enérgeia) que transforma uma coisa ou alguém, seja produzindo uma obra externa a esta atividade [...], seja produzindo tão somente essa atividade mesma (práxis no sentido estrito). É a atividade humana concreta, como dizia Marx (teses sobre Feuerbach, 1), da qual 0 trabalho é apenas um caso particular (2003, p. 467).

0 autor critica a definição de Althusser por parecer muito exígua, porque é entendida como "todo o processo de transformação de uma matéria-prima determinada, num produto determinado, transformação efetuada por um trabalho humano determinado, utilizando meios (de produção) determinados" (p. 466). Para Comte-Sponville, isso é dar demasiado peso à produção e ao trabalho, sendo melhor entendê-la de maneira mais ampla. 
0 outro verbete apresentado por Comte-Sponville, práxis (praxis), considera "o nome grego da ação; 0 nome esnobe ou marxista da prática'". Segundo ele, diferentemente da poíesis", a práxis é "uma ação que não visa nada além do seu bom desenrolar (sua eupraxía): ela não tende a nenhum fim externo a ela própria, nem nenhuma obra externa àquele que age" (p. 467). Dá como exemplo a vida, que é uma práxis: viver é criar sem obra.

Em Sociologia: conceitos-chave (SCOTT, 2010), Rob Stones, ao definir ação, afirma que são práticas humanas, ou seja, aquelas que as pessoas fazem individualmente. No âmbito coletivo, as ações dos atores dizem respeito às práticas sociais, que têm caráter compartilhado com membros de um determinado grupo.

0 tema da ação, que engloba as práticas individuais e sociais, preocupa a sociologia desde os primórdios, e De Certeau (1994, p. 42) enfatiza que a questão é complexa e pertencente a uma longa tradição que vem dos gregos, com passagens por Durkheim e Kant, os quais procuraram definir o que são essas operações, essas maneiras de fazer.

Weber, por sua vez, distinguia quatro tipos de ação social - "instrumental" e "relacionada a valores" (ações racionais) e "habituais" e "afetivas" (ações irracionais), que ele considerava como tipos ideais, sem existência distinta na vida real. Sua proposição foi retomada e avançada por outros sociólogos ao longo do tempo, entre eles Georg Simmel, que concordava sobre a importância de compreender a ação e a interação sociais com 0 objetivo de entender as estruturas sociais (DEVINE, 2010).

Nessa trajetória, as teorias que tratam da ação costumam ser divididas entre as que enfatizam a ordem social, ou seja, as restrições estruturais ou sistêmicas dos atores, e as que destacam a agência criativa e dinâmica dos atores, ou seja, seu papel ativo na vida social.

A crítica aos autores da primeira perspectiva, entre eles Talcott Parsons e os ligados ao estruturalismo francês, frutificou a partir do final da década de 1960, resultando na segunda perspectiva, que justapôs a discussão sobre ação e agência. Na primeira abordagem, destacam-se o pragmatismo e 0 interacionismo simbólico com os trabalhos de George Mead, Herbert Blumer e Erving Goffman. Na segunda, o neokantismo e a fenomenologia, a partir de Weber e Alfred Schütz, com Peter Berger e Thomas Luckmann, e Harold Garfinkel (STONES, 2010).

Em seu conjunto, essas perspectivas destacavam a reflexividade e a criatividade inerentes à interação dos sujeitos, o conhecimento acumulado que norteia adequadamente as práticas dos atores

Para aprofundamento do conceito, ver Outhwaite e Bottomore (1996); Edgar e Sedgwick (2003); Johnson (1997); Alexander et al (1994), entre outros.

Produção ou criação cujo fim não está em si mesmo, mas em seu resultado, que é externo a ela. São exemplos o trabalho e a arte (COMTE-SPONVILLE, 2003). 
frente a determinadas situações sociais (práticaspadrão), conjunto de competências, habilidades e compromissos morais vinculados às rotinas dos atores, e o papel do conhecimento tácito na produção de práticas sociais.

Uma terceira perspectiva surge para superar as dicotomias entre as correntes em oposição, na busca de um meio-termo que reconhecesse tanto as restrições das estruturas sociais quanto a agência dos atores. Seus principais representantes são Antony Giddens e Pierre Bourdieu, autores que souberam matizar esta correlação de elementos que constituem as práticas. Bourdieu com 0 conceito de "habitus" ${ }^{3}$ Giddens com 0 de "consciência prática", cujas ênfases mais complexas e sofisticadas nos atores, na ação e agência, permitiram "um melhor desenvolvimento da constituição e da dinâmica interna dos atores, e se concentrou nas formas profundas, mas sutis, pelas quais o mundo exterior os afeta" (STONES, 2010, p.14). Ambos são tributários da influência da fenomenologia, nas figuras de Schütz, Garfinkel e Goffman, os quais destacam em seus trabalhos a "consciência dos agentes individuais de que os outros esperam que se comportem de maneira adequada ao seu contexto social imediato" (p. 15). Stones ainda inclui Jürgen Habermas ${ }^{4}$, com sua noção de "mundo da vida" , no mesmo âmbito das discussões promovidas por Giddens e Bourdieu, os quais consideram o conhecimento dos agentes, como também faz a etnometodologia, aliando-o às bases sociais que 0 originou.

Tributário de toda essa herança, Michel De Certeau, em $A$ invenção do cotidiano: artes de fazer (1994), estudo empreendido entre 19741978, dedicou-se à compreensão das práticas cotidianas inseridas na cultura ordinária. Nessa pesquisa, ele e sua equipe estavam atrás das lógicas das práticas para esboçar "uma teoria das práticas cotidianas" (GIARD, 1994, p. 17). Para enfrentar a complexidade do problema, apela à semiótica e à filosofia analítica, além de apoiar-se em perspectivas socioantropológicas que teorizavam sobre as práticas, recorrendo principalmente a Goffman e a Bourdieu, somados aos ensinamentos da etnometodologia e da sociolinguística, especialmente através dos estudos de Garfinkel e Sacks, entre outros (GIARD, 1994).

Práticas, para De Certeau, são as maneiras de fazer e, formalmente, "[...] pode-se supor que essas operações multiformes e fragmentárias, relativas a ocasiões e a detalhes, insinuadas e

Para ele (1993, p. 72) "el habitus es el principio de mayor parte de las prácticas".

Além de duas outras correntes que apareceram nos últimos anos para implementar a discussão sobre as práticas sociais: a teoria das redes e a dos actantes. A primeira destaca a regularidade dos modos como as pessoas e coletividades se comportam e dos padrões dos vínculos que conectam os membros de estruturas sociais. 0 s atores ficam presos numa rede de relacionamentos que podem facilitar ou restringir suas ações, que ocorrem em meio às relações, práticas e estruturas sociais. Mais radical, a segunda corrente incorpora as máquinas como partes funcionais e significativas dos atores, os quais "seriam parte de uma rede homemmáquina de fluxos sociais, comunicação, dinheiro, fluidos e assim por diante [...]” (STONES, 2010, p.15). 
escondidas nos aparelhos das quais elas são os modos de usar, portanto, desprovidas de ideologias ou de instituições próprias, obedecem a regras" (1994, p. 42).

As noções oferecidas pelos autores citados anteriormente expõem os sentidos por eles atribuídos em torno do termo "práticas" e, ao mesmo tempo, sua complexidade. É importante considerar 0 contexto apresentado até 0 momento, pois é na noção de práticas que o presente artigo tem seu ponto de partida para tratar de práticas culturais, na tentativa de visualizar características das mesmas na sua (re)configuração a partir das tecnologias digitais.

Em outras palavras, pretende-se compreender como as práticas culturais são entendidas e quais são seus desdobramentos na esfera da cibercultura. Para tanto, o texto apresenta uma abordagem sobre as práticas culturais, os diferentes significados atribuídos por autores ao longo do tempo que implicam na compreensão a seu respeito. São utilizados como referências Bourdieu (1990 e 1995), De Certeau (1994), Coelho (1997), Maigret (2005).

Em um segundo momento, trata das práticas ciberculturais, apresentando o contexto e as características da cibercultura, os processos de consumo nela existentes e as práticas deles resultantes, as "maneiras de fazer", a partir das possibilidades que as tecnologias digitais e a internet oferecem. Utiliza-se como referências, além do próprio De Certeau (1994), autores como Lemos (2004), Jenkins (2008), Jensen (2010) e González (2012).

\section{Práticas Culturais:}

\section{o consumo e as táticas cotidianas}

Se a definição de práticas gera discordância entre os autores em função das diferenças entre seus pontos de vista sobre 0 tema, em relação ao termo "práticas culturais" ocorre 0 mesmo. Teixeira Coelho oferece duas versões significativas para 0 conceito de práticas culturais. Uma delas relaciona 0 termo igualmente às atividades de produção e recepção cultural: "escrever, compor, pintar e dançar são, sob este ângulo, práticas culturais tanto quanto frequentar teatro, cinema, concertos etc." (COELHO, 1997, p. 311). A outra versão considera como práticas culturais apenas as atividades envolvidas no campo da produção cultural, como a produção de um filme, um espetáculo ou uma ópera, por exemplo. As atividades relacionadas à recepção e ao consumo são consideradas hábitos culturais - "uma disposição duradoura adquirida pela reiteração de um ato" (p. 311): assistir filmes no cinema, peças teatrais, shows, exposições, etc.

0 entendimento sobre práticas culturais, no entanto, complexifica-se quando se contempla o pensamento de outros autores. Bourdieu desenvolve uma análise das práticas culturais a partir da relação entre os sentidos das práticas e as posições sociais. 0 autor faz uma divisão 
entre os sujeitos das práticas: aqueles que chama de privilegiados (por serem herdeiros de tradições culturais e de uma formação escolar excelente) e de marginalizados (as classes populares que não tiveram acesso a uma formação ideal). A análise de Bourdieu associa as disposições sociais herdadas (o que chama de "habitus") com os gostos dos indivíduos, sendo o segundo condicionado pela primeira - as disposições sociais -, a qual também condiciona a capacidade de os indivíduos consumirem os bens considerados cultos (pelo alcance a eles, pelo tempo disponível ou por sua capacidade simbólica), limitando 0 acesso às práticas relacionadas a eles (BOURDIEU, 1990; 1995).

A crítica ao pensamento de Bourdieu emerge por ele centralizar a questão das práticas culturais nas camadas sociais privilegiadas, sem questionar sua qualidade cultural, e não considerar "todo o continente das práticas cotidianas" e da complexidade dos consumos midiáticos dos privilegiados e das camadas populares (MAIGRET, 2005, p. 216). Em oposição ao seu pensamento, Jean-Claude Passeron e Claude Grignon apontam a necessidade de se reconhecer as dificuldades por quais passam as culturas populares e valorizar a riqueza de seus conteúdos (MAIGRET, 2005).

Por sua vez, Maigret observa que as práticas culturais não podem ser definidas pela relação entre as características sociodemográficas dos sujeitos e os meios culturais (livros, filmes, obras de arte, TV, teatros, etc.) que utilizam. Para 0 autor, "as obras circulam em meios diversos sem respeitar as barreiras correspondentes aos gostos [...], são objeto de eleição contraditórias por parte de públicos relativamente homogêneos" (p. 226). Assim, compreende como impossível "pensar os grupos sociais pelos produtos que utilizam" (p. 227). Ou seja, considera que não há relação direta entre as práticas culturais e as posições sociais.

Em consonância com Maigret, De Certeau (1994), tributário do pensamento jesuítico renascentista, oferece uma interpretação para compreender 0 impasse sobre as práticas culturais e a posição social e cultural dos indivíduos. 0 autor reconhece uma capacidade de resistência dos indivíduos perante o que é dado pela produção cultural (dita dominante) em seus diferentes meios - 0 que regulamenta 0 acesso e 0 uso aos bens. Para De Certeau, os comportamentos se definem de acordo com o lugar em que se encontram socialmente, sendo configurados através de "modalidades de ação" ou "formalidades" das práticas em determinado lugar/ contexto. Entretanto, apesar das práticas culturais se configurarem em certo lugar/contexto, não se restringem às modalidades neles existentes. $0 \mathrm{~s}$ sujeitos, que chama de consumidores, desenvolvem táticas, "atos fugazes de resistência", "competências fundamentais, universalmente presentes" (MAIGRET, 2005, pp. 232-233), as quais lhes permitem experimentar, aprender, descobrir em torno do que é oferecido como referência.

Segundo De Certeau (1994), as práticas culturais dos consumidores são do tipo tático. Tática é a 
ação calculada que "é determinada pela ausência de um próprio ${ }^{6}$. Então, nenhuma delimitação de fora lhe fornece a condição de autonomia" ( $p$. 100). Ela desdobra-se em "maneiras de fazer", "maneiras de utilizar a ordem imposta do lugar", a partir de necessidades de adequá-la a situações particulares, produzindo "estilos de ação" próprios (caminhar, ler, produzir, falar, etc.), os quais acabam por representar "funcionamentos diferentes e interferentes" (pp. 92-93). Esses estilos de ação partem de um campo que os regula - o sistema da indústria, por exemplo -, mas introduzem nele outras regras, através das quais constituem novos formatos de produtos culturais? Assim, as práticas culturais dos consumidores são resultantes de um "fazer com", com a oferta que já existe, mas à sua maneira, à forma de seus interesses (DE CERTEAU, 1994).

Maigret exemplifica a ideia de De Certeau observando os comerciais que passam nos intervalos dos telejornais. Reconhece que os telespectadores não podem mudar 0 conteúdo que eles transmitem, uma vez que não têm acesso às estratégias de produção dos mesmos, mas diz ser "sempre possível desenvolver táticas temporárias de desvio: fazer zapping, arrumar a mesa, conversar, submergir em algumas publicidades evadindo-se delas ou nelas (através da ironia, esquecimento, adesão parcial) " (2005, p. 234).

As maneiras diferenciadas de exercer uma prática acabam proporcionando alterações no cenário de referência. "Sem sair do lugar onde tem que viver e que lhe impõe uma lei, ele aí instaura pluralidade e criatividade. Por uma arte de intermediação, ele tira daí efeitos imprevistos" (DE CERTEAU, 1994, p. 93). E é por que os indivíduos interferem nos contextos em que vivem que De Certeau entende que não se pode identificar ou qualificá-los conforme os produtos culturais que consomem; é preciso considerar o "uso que fazem deles", suas práticas de consumo. 0 autor observa que, no caso do consumo cultural, "poder-se-ia quase afirmar que a produção fornece 0 capital e os usuários, como locatários, adquirem o direito de efetuar operações sobre este fundo sem serem os seus proprietários" (DE CERTEAU, 1994, p. 96).

De Certeau compreende que "as maneiras de fazer", "os modos de emprego" referentes às práticas se desenvolvem cada vez mais, pois são proporcionais

0 autor refere-se à ausência de poder direcionador. "Próprio" para ele significa um "lugar de poder" que postula normas direcionadoras (DE CERTEAU, 1994, p. 102).

É nesse sentido que podemos entender a noção de "tática" em oposição à de "estratégia", conforme propõe De Certeau (1994). Enquanto as estratégias são "ações que, graças ao postulado de um lugar de poder (a propriedade de um próprio), elaboram lugares teóricos (sistemas e discursos totalizantes), capazes de articular um conjunto de lugares físicos onde as forças se distribuem" (p.102), a tática seria determinada pela ausência de poder e por isso mesmo tem que utilizar "as falhas que as conjunturas particulares vão abrindo na vigilância do poder proprietário. Aí vai caçar. Cria ali surpresas. Consegue estar onde ninguém espera. É astúcia" (p.100).

De Certeau (1994) lembra que são a esses usos diferenciados, os quais acabam interferindo no próprio contexto que os gera, que se atribui como causa da "vulgarização" ou "degradação da cultura", justamente por alterar o que nela já se dá por definido. 
ao movimento dos sujeitos que (re)criam formas de agir, a fim de se adaptar e identificar com os lugares nos quais se encontram, substituindo ou recriando métodos de agir nos mesmos. Nessa perspectiva, para ele, os bens culturais "são o repertório com 0 qual os usuários procedem a operações próprias, são o léxico de suas práticas" (p. 93).

Daí pode-se entender que as práticas culturais são fruto das ações humanas que se configuram e reconfiguram no confronto entre "poderes instituídos" e os sujeitos que, a partir de suas táticas, buscam ajustar-se a seus cenários e circunstâncias. Na sociedade atual, essa reconfiguração ocorre também a partir das possibilidades que surgem com a crescente utilização das tecnologias digitais e a formação de redes telemáticas, as quais potencializam as ações táticas dos sujeitos em um nível planetário.

\section{Práticas ciberculturais: as táticas em rede}

Para André Lemos (2005, on-line), a cibercultura é regida pelo princípio da "re-mixagem", baseada no "conjunto de práticas sociais e comunicacionais de combinações, colagens, cut-up de informação

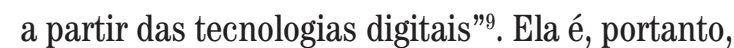
um "território recombinante", caracterizada principalmente pela potencialização das formas individualizadas de emissão $0^{10}$; pela facilidade da conexão em rede; e pela configuração de formatos midiáticos e práticas sociais (LEMOS, 2009).

É possível perceber, assim, duas importantes transformações proporcionadas pelas tecnologias digitais: no modelo de produção da informação, que passa a utilizar o processo microeletrônico, e no seu modo de difusão e circulação, os quais, baseados no modelo rizomático das redes, têm nos processos colaborativos uma de suas forças propulsoras. Nesse sentido, falar em novas formas de produção (de bens, serviço, informação, etc.) implica também em falar em uma reconfiguração nas formas de consumo, já que este (o consumo) também é uma forma de produção, que se caracteriza por ser astuciosa, dispersa e quase invisível, "pois não se faz notar com produtos próprios, mas nas maneiras de empregar os produtos impostos por uma ordem econômica dominante" (DE CERTEAU, 1994, p. 39).

Entretanto, há que se reconsiderar essa invisibilidade e dispersão nas atuais práticas

0 autor ressalta, no entanto, que a recombinação, a cópia e apropriação de diversos elementos, sejam eles produtivos, religiosos ou artísticos, são sempre um traço constitutivo de toda formação cultural. Em consonância com a perspectiva de Garcia Canclini sobre o hibridismo cultural, Lemos $(2009$, p.38) afirma que toda cultura envolve "[...] formação de hábitos, costumes e processos sócio-técnico-semióticos que se dão sempre a partir do acolhimento de diferenças e no trato com outras culturas". E, nesse sentido, o autor argumenta que não é a recombinação em si a novidade da cibercultura, mas a forma, a velocidade e 0 alcance global que esse movimento passa a ocorrer nas sociedades contemporâneas.

100 autor chama de "liberação dos pólos de emissão", que caracterizaria ainda o surgimento de mídias "pós-massivas". Entretanto, concordamos com Primo (2013) que o "pós-massivo" não pode ser compreendido como uma superação ou ultrapassagem das mídias de massa: "Uma realidade 'pós-massiva', portanto, poderia ser apenas defendida no sentido de que a mídia de massa deixou de ser a fonte básica de informações [...]” (p. 27). 
culturais, incluindo aí as práticas de consumo, já que, com a internet, essas diferentes "maneiras de fazer" dos consumidores tornam-se visíveis e rastreáveis. Mais do que isso, as tecnologias digitais e a internet possibilitam uma maior descentralização nas formas de produção e de distribuição de conteúdos, permitindo que os consumidores produzam não apenas "maneiras de empregar" os produtos que lhe são impostos, mas, também, seus próprios produtos. Afinal, conforme afirma Lemos (2009, p.39), a cibercultura "[...] instaura uma estrutura midiática ímpar [...] na qual, pela primeira vez, qualquer indivíduo pode produzir e publicar informação em tempo real, sob diversos formatos e modulações, adicionar e colaborar em rede com outros, reconfigurando a indústria cultural ('massiva')”. É nesse sentido que podemos compreender como práticas culturais tanto as atividades de produção quanto as de recepção (COELHO, 1997), já que ambas se constituem como campos de produção simbólica.

\section{A cibercultura, portanto, configura-se como} uma das esferas em que se pode observar, de forma mais clara, as práticas culturais no sentido proposto de De Certeau. Assim como um estrangeiro "cria para si um espaço de jogo para maneiras de utilizar a ordem imposta do lugar ou da língua", ou os indígenas que, mesmo subjugados, "usavam as leis, as práticas ou as representações que lhes eram impostas pela força ou pela sedução, para outros fins que não os dos conquistadores" (DE CERTEAU, 1994, pp. 94-95), também podemos compreender muitas práticas ciberculturais, em especial as relacionadas à Web 2.0, como sendo do tipo "tático", pois é aí que o "fraco" ganha poder de fala e de visibilidade - seja por meio de um blog, podcast, $v \log ^{11}$ ou perfil nas redes sociais.

Essas diferentes "maneiras de empregar", das quais fala De Certeau, tornam-se ainda mais evidentes nos dias de hoje com a crescente popularização dos dispositivos móveis de comunicação, os quais ampliaram significativamente a capacidade de os sujeitos produzirem conteúdos "em tempo real", no momento dos acontecimentos, trazendo à tona as diversas narrativas em torno de um mesmo fato. A cobertura da chamada "Mídia Ninja" sobre as manifestações que tomaram as ruas de diversas cidades brasileiras nos meses de junho e julho de 2013 é um exemplo emblemático de ampliação do poder de fala e de visibilidade do "fraco", na medida em que o streaming dos eventos via smartphones passa a ser visto como "tática" de proteção contra os abusos da polícia, cujas ações estavam sendo acompanhadas ao vivo por milhares de pessoas, e como uma alternativa à cobertura da grande mídia, chegando a obter picos de 25 mil espectadores on-line (BENTES, 2013).

Além desse estado de vigilância e visibilidade, as tecnologias e as redes digitais também possibilitam a subversão de certas lógicas de consumo típicas dos meios massivos: seja por 
meio de sistemas como o $\mathrm{RSS}^{12}$, que permite às pessoas "assinarem" apenas os conteúdos web de seu interesse e acessá-los na hora que quiserem; do compartilhamento em grande escala de conteúdos digitais sem a autorização dos detentores dos direitos autorais (pirataria); ou até mesmo com a apropriação de narrativas já existentes para criar e disponibilizar em rede novas histórias, tais como as fanfictions ${ }^{13}$.

\section{A cibercultura também é marcada pela} intensificação de práticas colaborativas em níveis planetários ${ }^{14}$, como ocorre nas plataformas wikis, como a Wikipédia ${ }^{15} ;$ em práticas profissionais diversas, vide a consolidação do "jornalismo colaborativo"16; ou no modelo e financiamento coletivo, o chamado crowfunding ${ }^{17}$. Em todo caso, o que podemos notar é que essas práticas ciberculturais se baseiam amplamente na colaboração entre os sujeitos, tanto na forma de produzir quanto na de consumir e fazer circular os produtos e a informação digital, embaralhando as fronteiras até então bem definidas desses processos. Assim, o entendimento das práticas culturais contemporâneas passa também pela compreensão do fenômeno de convergência atualmente em curso.

Para Jenkins (2008), o processo de convergência que impacta a sociedade atual é um fenômeno que extrapola as questões técnicas e que envolve também a ação e as práticas de produtores e consumidores de conteúdos midiáticos. Essas ações dizem respeito a um processo de mão dupla que ocorre tanto de "cima para baixo", no âmbito corporativo, envolvendo "materiais e serviços produzidos comercialmente, circulando por circuitos regulados e previsíveis", quanto de "baixo para cima", à medida que os "consumidores estão aprendendo a utilizar as diferentes tecnologias para ter um controle mais completo sobre o fluxo da mídia e para interagir com outros consumidores" (JENKINS, 2008, p. 44). Por isso, 0 autor defende que 0 processo de convergência deve ser compreendido como uma transformação das práticas culturais.

Também a fim de pautar um entendimento que ultrapasse a visão tecnicista sobre 0 conceito de convergência, Jensen (2010) propõe a

0 RSS (Real Simple Syndication) é um sistema de distribuição de conteúdo na internet recebida de forma automática em um agregador de conteúdo, tal como 0 Google Reader.

13 São as histórias de ficção criadas por fãs.

14 Para 0 aprofundamento sobre a cultura da participação, ver Shirky (2012).

15 Sobre práticas colaborativas na Wikipédia, ver Campos (2013).

16 Ou jornalismo participativo ou ainda jornalismo open source. Para mais informações, ver Brambilla (2005); Primo e Trasel (2006); Belochio (2010).

17 É um tipo de financiamento coletivo, desenvolvido principalmente por meio da internet, e voltado para a obtenção de recursos para a realização de uma iniciativa. Os fins são os mais diversos, projeto de jornalismo cidadão; campanhas políticas, filantropia, realização de filmes, livros, shows, etc. 
compreensão desse processo a partir da interrelação da comunicação interpessoal, meios de massa e redes digitais ${ }^{18}$, dando ênfase às práticas que surgem a partir da materialidade dos meios. Para 0 autor, os meios digitais complexificam o processo de comunicação, pois reproduzem e recombinam "[...] todos os meios anteriores de representação e de interação em uma única plataforma material de hardware e software"19 (pp. 69-70), suportando, assim, várias práticas comunicativas e, portanto, culturais. Dessa forma, certas práticas se desenvolvem em diferentes meios, enquanto outras retornam com 0 aparecimento de novas plataformas ${ }^{20}$ (JENSEN, 2010). De acordo com Aquino (2012), são essas práticas comunicativas e as interações que decorrem delas que caracterizam os intercâmbios, os processos de convergência, na medida em que o panorama comunicacional atual, cada vez mais, passa a ser marcado pela "multiplicidade de meios e pela versatilidade de papéis que os indivíduos assumem nos processos de comunicação, ora de emissores, ora de receptores" (p.63).

Nesse sentido, concordamos com Martín-Barbero (2006, p.54) que afirma que, mais do que uma gama de novas máquinas, essa "revolução tecnológica introduz em nossa sociedade [...] um novo modo de relação entre os processos simbólicos - que constituem o cultural - e as formas de produção e distribuição dos bens e serviços: um novo modo de produzir, confusamente associado a um novo modo de comunicar". Portanto, para compreendermos uma cultura, é preciso refletir sobre a produção e a troca de formas simbólicas que nela ocorrem, 0 que, na sociedade atual, implica nos estudos sobre os meios de comunicação e seus impactos, já que "o desenvolvimento dos meios de comunicação é, em sentido fundamental, uma reelaboração do caráter simbólico da vida social" (THOMPSON, 1998, p. 19).

Essa produção simbólica varia conforme a cultura em que está inserida e, da mesma maneira que não se pode falar de uma única cultura, a cibercultura também só existe no plural - cibercultur@s -, segundo atenta González (2012). Para este autor, o processo de desenvolvimento e difusão das tecnologias no espaço social comporta-se como um vetor, ou seja, como uma força com direção. "É uma força com magnitude, porque com ela fazem-se coisas, tecem-se significados e fazem-se produzir coisas para os outros. Essa magnitude depende não apenas das especificidades técnicas do inventor ou dispositivo, mas também do entorno social no qual se desenvolve, se arraiga ou se adapta" (GONZÁLEZ, 2012, p. 33). A partir desse contexto de relações sociais são criadas as condições para que um determinado

18 Para Jensen (2010), esses são os três graus de materialização dos meios.

19 Tradução das autoras para: "[...] reproduces and recombines all previous media of representation and interaction on a single material platform of hardware and software".

200 autor cita como exemplo a troca de mensagem de texto e 0 aparelho celular. 
desenvolvimento tecnológico possibilite uma revolução nas formas de se produzir, organizar e representar a si mesmas das sociedades concretas ou, então, em outro local ou sistema sociotécnico, seja uma mera ferramenta de "uso restrito a facilitar operações práticas" (p. 33).

A partir do diálogo entre a Economia

Política da Comunicação e o Paradigma da Complexidade, Gonzaléz propõe o entendimento da cibercultur@ ${ }^{21}$ como um processo que se concretiza no "redesenho de três cultivos de nossas habilidades práticas e representações sobre: a informação, o conhecimento e a comunicação" (p.38). De acordo com 0 autor, essas são as três capacidades que devem ser cultivadas na busca de uma crescente autodeterminação frente à solução de problemas nas diferentes sociedades e é a junção dessas três capacidades que configuram a cibercultura.

González (2012) argumenta que os conhecimentos e as estruturas organizacionais necessários para gerar novo saber e, consequentemente, novas tecnologias se originam, vivem, armazenam e distribuem em uma área dispersa que, por efeito da acumulação de energia social, coloca certos países em situação desvantajosa, desde as origens dos seus processos de colonizaçã $0^{22}$. Entretanto, mesmo que as tecnologias digitais, assim como todas as outras tecnologias, ajam como vetores de determinadas forças dos que ocupam a centralidade de um sistema-mundo, ainda assim passam por diferentes formas de apropriação social que, em um olhar mais cuidadoso sobre esses fenômenos, evidenciam "astúcia" daqueles que se encontram nas zonas periféricas e intermediárias desse sistema.

Um dos exemplos brasileiros mais icônicos é 0 modelo open business do tecnobrega, surgido na periferia de Belém do Pará. Não há dúvidas de que esse modelo de negócio, o qual reconfigurou a indústria fonográfica local, servindo de modelo para o restante do país e do mundo, só se tornou viável com as possibilidades trazidas pelas tecnologias digitais, que permitiram aos artistas produzirem e distribuírem suas próprias músicas. "A popularização do computador, o domínio de novas tecnologias pelos artistas da periferia de Belém e a inserção de batidas eletrônicas na música brega produziram a multiplicação de estúdios caseiros e facilitaram a produção do tecnobrega para uma maior quantidade e diversidade de artistas" (LEMOS et al., 2008. p.48).

Esse modelo de negócio baseado na apropriação tecnológica das periferias também é o que

210 autor opta por utilizar o símbolo "arroba” (@) porque, sendo similar à figura de um caracol, remete "[...] a um ciclo de retroalimentação positiva", delineado a partir das "modulações recentes relacionadas com as tecnologias digitais e a comunicação mediada por computadores diante do desenvolvimento de formas criativas de cognição coletiva" (GONZÁLEZ, 2012, p. 17).

22 Isso ocorre "não por incapacidade natural de geração de tecnologias ou conhecimentos, mas por efeito da divisão social do trabalho, por relações históricas de força e poder de imposição" (GONZÁLEZ, 2012, p. 33). 
caracteriza "Nollywood", a indústria de cinema da Nigéria, que se sustenta, de igual forma, pelas facilidades das tecnologias digitais para produzir seus filmes e pela rede de camelôs para vendê-los. É de se surpreender que um país, onde quase não existem salas de cinema, seja a terceira maior receita do mundo cinematográfico, produzindo cerca de US\$ 200 milhões por ano e empregando mais de um milhão de pessoas ${ }^{23}$. Desse modo, as periferias locais estão se apropriando das novas tecnologias para criar suas próprias redes de produção, distribuição e consumo de cultura (LEMOS et al, 2008).

É a partir desses cenários que podemos perceber que a "astúcia" dos sujeitos pode ser observada não apenas na forma de consumir os produtos, mas também na maneira de produzi-los, uma vez que o cenário de convergência em curso não somente borra as fronteiras entre produtor e consumidor, como também complexifica a distinção das operações táticas e estratégicas, na medida em que as práticas culturais dos sujeitos se impõem cada vez mais frente aos poderes instituídos.

\section{Considerações finais}

A proposição deste texto foi de expandir a reflexão sobre práticas culturais e sua importância para analisar a agência dos sujeitos em relação a toda e qualquer tecnologia - no caso específico, com as digitais -, as quais possibilitam processos e ações convergentes, em fluxo e em tempo real. Esta é uma transformação radical na cultura contemporânea proporcionada pela revolução tecnológica, que alterou as dimensões temporais e espaciais e, com isso, grande parte da forma de estar no mundo e os modos de fazer e agir.

Para tal, o ponto de partida foi a recuperação de algumas definições de práticas em seu sentido mais genérico e amplo, com o intuito de assentar as bases para conceituar práticas culturais e, logo, as ciberculturais, com o objetivo de conceber estas últimas pela perspectiva da cultura e não apenas como consequência da tecnologia em si.

Nesse âmbito, é no seio da sociologia que se origina a preocupação em entender as vinculações entre indivíduo, ação e sociedade. Assunto com longo percurso nessa disciplina, tratado de maneira até antagônica por autores identificados com perspectivas e tradições diferentes, embora os vindos da fenomenologia, da etnometodologia, do interacionismo simbólico e da sociologia da vida cotidiana concordem com a importância das práticas dos sujeitos para 0 entendimento tanto para a vida social como cultural.

Na perspectiva cibercultural, procurou-se refletir sobre como as tecnologias digitais e as redes telemáticas têm reconfigurado o cenário 
sociocultural contemporâneo, na medida em que possibilitam uma crescente troca de bens simbólicos e processos de compartilhamento de diversos elementos da cultura, gerando, assim, novas práticas culturais. Esse cenário é marcado profundamente pelo fenômeno da convergência, 0 qual borra qualquer fronteira até então delimitada entre a produção e a recepção/consumo e os processos localizados entre as duas esferas, permitindo que as práticas produtivas dos sujeitos ultrapassem a questão da produção de significado que ocorre no ato de consumo, alcançando, ainda, o nível da produção de bens culturais.

É a partir dessas reconfigurações proporcionadas pelas práticas ciberculturais que podemos compreender o termo "cibercultura", não apenas como 0 "mundo dos computadores", mas ligado ao prefixo cyber - do grego Kubernetes -, que se refere à capacidade de dirigir, de governar-se, de construir saídas inteligentes frente a problemas que parecem impossíveis de resolver, conforme ressalta González (2012). Desse modo, entendemos que muitas das atuais práticas ciberculturais, como as exemplificadas ao longo deste trabalho, demonstram exatamente essa vontade dos sujeitos em alcançar maior autonomia frente às estratégias das grandes indústrias, em especial as midiáticas.

\section{Referências}

ALEXANDER, Jeffrey C. et al. (Org.). El vínculo micromacro. Guadalajara: Universidad de Guadalajara, 1994. AQUINO, Maria Clara. Convergência entre Televisão e Web: proposta de categorização analítica. 2012. 208 f. Tese (Doutorado em Comunicação e Informação) Faculdade de Biblioteconomia e Comunicação, UFRGS, Porto Alegre, 2012.

BELOCHIO, Vivian. 0 movimento Pro-Am e a prática da colaboração nos meios informativos: especificidades do jornalismo colaborativo em redes digitais. Verso e Reverso, v.24, $n^{0} 57$. São Leopoldo, 2010.

BENTES, Ivana. Prefácio. In: MALINI, Fábio; ANTOUN, Henrique. A Internet e a Rua: ciberativismo e mobilização nas redes sociais. Porto Alegre: Sulina, 2013, pp. 9-16.

BOURDIEU, Pierre. Sociología y Cultura. México: Grijalbo, 1990.

Cosas Dichas. Barcelona: Gedisa, 1993. Respuestas por una Antropología

Reflexiva. México: Grijalbo, 1995.

BRAMBILLA, Ana Maria. A reconfiguração do jornalismo através do modelo open source. Sessões do imaginário, v. 10, $\mathrm{n}^{0}$ 13, 2005.

CAMP0S, Aline de. Os conflitos em processos colaborativos de escrita coletiva na web 2.0. In: PRIMO, Alex (Org.). Interações em Rede. Porto Alegre: Sulina, 2013, pp.163-188.

COELHO, Teixeira. Dicionário Crítico de Política

Cultural. São Paulo: Iluminuras, 1997.

COMTE-SPONVILLE, André. Dicionário Filosófico. São Paulo: Marins Fontes, 2003.

DE CERTEAU, Michel. A Invenção do Cotidiano: artes de fazer. Petrópolis: Vozes, 1994.

DEVINE, Fiona. Ação racional. In: SCOTT, John (Org.). Sociologia: conceitos-chave. Rio de Janeiro: Zahar, 2010.

EDGAR, Andrew; SEDGWICK, Peter (Orgs). Teoria Cultural de A Z. Conceitos-chave para entender 0 mundo contemporâneo. São Paulo: Contexto, 2003. 
GONZÁLEZ, Jorge A. Entre Cultura(s) e

Cibercultur@(s): incursões e outras rotas não lineares. São Bernardo do Campo: Universidade Metodista de São Paulo, 2012.

JENKINS, Henry. Cultura da Convergência. São Paulo: Aleph, 2008.

JENSEN, Klaus B. Media Convergence: the three degrees of network, mass, and interpersonal communication. New York: Routledge, 2010.

JOHNSON, Allan G. Dicionário de Sociologia. Guia prático da linguagem sociológica. Rio de Janeiro: Zahar, 1997.

LEMOS, André. Ciber-cultura-remix. São Paulo: Itaú Cultural, 2005. Disponível em < http://www.facom.ufba. br/ciberpesquisa/andrelemos/remix.pdf. $>$. Acesso em 15 set. 2013.

. Cibercultura como território recombinante.

In: TRIVINHO, Eugênio; CAZELOTO, Edilson (Org.). A cibercultura e seu espelho: campo de conhecimento emergente e nova vivência humana na era da imersão interativa. São Paulo: ABCiber; Instituto Itaú Cultural, 2009, pp. 38-46.

LEMOS, Ronaldo et al. Tecnobrega: o Pará reinventando o negócio da música. Rio de Janeiro: Aeroplano, 2008.

MAIGRET, Eric. Sociologia de la Comunicación y los Medios. Bogotá: Fondo de Cultura Económica, 2005.

MARTÍN-BARBER0, Jesús. Tecnicidades, identidades, alteridades: mudanças e opacidades da comunicação no novo século. In: MORAES, Denis (Org.). Sociedade

Midiatizada. Rio de Janeiro: Mauad, 2006, pp.51-80.

De los medios a las prácticas. In: OROZC0, Guillermo (Org.). La comunicación desde las prácticas sociales. Reflexiones en torno a su investigación.

Cuadernos de Comunicación y prácticas sociales, $n$. 1. Mexico: Universidade Iberoamericana, 1990.

PRIMO, Alex; TRÄSEL, Marcelo. Webjornalismo participativo e a produção aberta de notícias.
Contracampo (UFF), n. 14, v.2, pp. 37-56, 2006.

. Interações Mediadas e Remediadas:

controvérsias entre as utopias da Cibercultura e a grande indústria midiática. In: PRIMO, Alex (Org.). Interações em Rede. Porto Alegre: Sulina, 2013, pp.13-32.

OUTHWAITE, William; BOTTOMORE, Tom (Eds.).

Dicionário do pensamento social do século XX. Rio de Janeiro: Zahar, 1996.

SHIRKY, Clay. A Cultura da Participação: criatividade e generosidade no mundo conectado. Rio de Janeiro: Jorge Zahar, 2012.

SCOTT, John (Org.). Sociologia: conceitos-chave. Rio de Janeiro: Zahar, 2010.

THOMPSON, John B. A Mídia e a Modernidade. Uma Teoria Social da Mídia. Petrópolis, RJ: Vozes, 1998. 


\begin{tabular}{|c|c|}
\hline $\begin{array}{l}\text { Cultural and Cybercultural } \\
\text { Practices: thinking the relationship } \\
\text { with technologies }\end{array}$ & $\begin{array}{l}\text { Prácticas Culturales y } \\
\text { Ciberculturales: para pensar la } \\
\text { relación con las tecnologías }\end{array}$ \\
\hline $\begin{array}{l}\text { Abstract } \\
\text { The purpose of this text is to expand the reflection on } \\
\text { cultural practices and its importance to analyze ways } \\
\text { of doing and acting in the digital context, considering } \\
\text { its convergent processes, under the logic of real time. } \\
\text { First of all, it recovers the generic sense of practice } \\
\text { in order to lay the foundations for a understanding } \\
\text { of what constitutes cultural practices, reflecting on } \\
\text { the different meanings attributed by authors such } \\
\text { as Pierre Bourdieu, Michel De Certeau, Teixeira } \\
\text { Coelho and Eric Maigret. In a second step, the paper } \\
\text { is directed to the context and characteristics of } \\
\text { cyberculture, its consumer processes and practices, } \\
\text { resulting from the changes raised by the Internet and } \\
\text { digital technologies. } \\
\text { Keywords } \\
\text { Cultural practices } 1 \text {. Technologies } 2 . \text { Cyberculture } 3 .\end{array}$ & $\begin{array}{l}\text { Resumen } \\
\text { El propósito de este texto es ampliar la reflexión sobre } \\
\text { las prácticas culturales y su importancia para analizar } \\
\text { las formas de hacer y de actuar en el contexto digital, } \\
\text { sus procesos y acciones convergentes, en flujo y en } \\
\text { tiempo real. En primer lugar, se recupera la definición } \\
\text { de práctica en su sentido más genérico, con el fin } \\
\text { de sentar las bases para la comprensión de lo que } \\
\text { constituyen prácticas culturales, con base en los } \\
\text { diferentes significados atribuidos por autores como } \\
\text { Pierre Bourdieu, Michel De Certeau, Teixeira Coelho } \\
\text { y Eric Maigret. En una segunda etapa, el articulo está } \\
\text { dirigido para el contexto y las características de la } \\
\text { cibercultura, los procesos y prácticas del consumo que } \\
\text { surgen con las tecnologías digitales y la internet. } \\
\text { Palabras clave } \\
\text { Prácticas culturales 1. Tecnologías } 2 . \text { Cibercultura } 3 .\end{array}$ \\
\hline
\end{tabular}




\section{Expediente}

A revista E-Compós é a publicação científica em formato eletrônico da Associação Nacional dos Programas de Pós-Graduação em Comunicação (Compós). Lançada em 2004, tem como principal finalidade difundir a produção acadêmica de pesquisadores da área de Comunicação, inseridos em instituições do Brasil e do exterior.

\section{E-COMPÓS I www.e-compos.org.br I E-ISSN 1808-2599}

Revista da Associação Nacional dos Programas de Pós-Graduação em Comunicação.

Brasília, v.19, n.1, jan./abr. 2016.

A identificação das edições, a partir de 2008, passa a ser volume anual com três números.

Indexada por Latindex I www.latindex.unam.mx

\section{CONSELHO EDITORIAL}

Alexandre Farbiarz, Universidade Federal Fluminense, Brasil Alexandre Rocha da Silva, Universidade Federal do Rio Grande do Sul, Brasil Ana Carolina Damboriarena Escosteguy, Pontifícia Universidade Católica do Rio Grande do Sul, Brasil

Ana Carolina Rocha Pessôa Temer, Universidade Federal de Goiás, Brasil Ana Regina Barros Rego Leal, Universidade Federal do Piaú, Brasil Andrea França, Pontifícia Universidade Católica do Rio de Janeiro, Brasil André Luiz Martins Lemos, Universidade Federal da Bahia, Brasil Antonio Carlos Hohlfeldt, Pontifícia Universidade Católica do Rio Grande do Sul, Brasil

Arthur Ituassu, Pontifícia Universidade Católica do Rio de Janeiro, Brasil Álvaro Larangeira, Universidade Tuiuti do Paraná, Brasil

Ângela Freire Prysthon, Universidade Federal de Pernambuco, Brasil César Geraldo Guimarães, Universidade Federal de Minas Gerais, Brasil Cláudio Novaes Pinto Coelho, Faculdade Cásper Líbero, Brasil Daisi Irmgard Vogel, Universidade Federal de Santa Catarina, Brasil Denize Correa Araujo, Universidade Tuiuti do Paraná, Brasil Eduardo Antonio de Jesus, Pontifícia Universidade Católica de Minas Gerais, Brasil

Daniela Zanetti, Universidade Federal do Espirito Santo, Brasil Eduardo Vicente, Universidade de São Paulo, Brasil Elizabeth Moraes Gonçalves, Universidade Metodista de São Paulo, Brasil Erick Felinto de Oliveira, Universidade do Estado do Rio de Janeiro, Brasil Francisco Elinaldo Teixeira, Universidade Estadual de Campinas, Brasil Francisco Paulo Jamil Almeida Marques, Universidade Federal do Paraná, Brasil

Gabriela Reinaldo, Universidade Federal do Ceará, Brasil Goiamérico Felício Carneiro Santos, Universidade Federal de Goiás, Brasil Gustavo Daudt Fischer, Universidade do Vale do Rio dos Sinos, Brasil Herom Vargas, Universidade Municipal de São Caetano do Sul, Brasil Itania Maria Mota Gomes, Universidade Federal da Bahia, Brasil
Janice Caiafa, Universidade Federal do Rio de Janeiro, Brasil Jiani Adriana Bonin, Universidade do Vale do Rio dos Sinos, Brasil José Afonso da Silva Junior, Universidade Federal de Pernambuco, Brasil José Luiz Aidar Prado, Pontifícia Universidade Católica de São Paulo, Brasil Juçara Gorski Brittes, Universidade Federal de Ouro Preto, Brasil Kati Caetano, Universidade Tuiuti do Paraná, Brasil Lilian Cristina Monteiro França, Universidade Federal de Sergipe, Brasil Liziane Soares Guazina, Universidade de Brasilia, Brasil Luíza Mônica Assis da Silva, Universidade de Caxias do Sul, Brasil Luciana Miranda Costa, Universidade Federal do Pará, Brasil Malena Segura Contrera, Universidade Paulista, Brasil Maria Ogécia Drigo, Universidade de Sorocaba, Brasil Maria Ataide Malcher, Universidade Federal do Pará, Brasil Marcia Tondato, Escola Superior de Propaganda e Marketing, Brasil Marcel Vieira Barreto Silva, Universidade Federal da Paraíba, Brasil Maria Clotilde Perez Rodrigues, Universidade de São Paulo, Brasil Maria das Graças Pinto Coelho, Universidade Federal do Rio Grande do Norte, Brasil

Mauricio Ribeiro da Silva, Universidade Paulista, Brasil

Mauro de Souza Ventura, Universidade Estadual Paulista, Brasil Márcio Souza Gonçalves, Universidade do Estado do Rio de Janeiro, Brasil Micael Maiolino Herschmann, Universidade Federal do Rio de Janeiro, Brasil Mirna Feitoza Pereira, Universidade Federal do Amazonas, Brasil Nísia Martins Rosario, Universidade Federal do Rio Grande do Sul, Brasil Potiguara Mendes Silveira Jr, Universidade Federal de Juiz de Fora, Brasil Regiane Regina Ribeiro, Universidade Federal do Paraná, Brasil Rogério Ferraraz, Universidade Anhembi Morumbi, Brasil Rose Melo Rocha, Escola Superior de Propaganda e Marketing, Brasil Rozinaldo Antonio Miani, Universidade Estadual de Londrina, Brasil Sérgio Luiz Gadini, Universidade Estadual de Ponta Grossa, Brasil Simone Maria Andrade Pereira de Sá, Universidade Federal Fluminense, Brasil Veneza Mayora Ronsini, Universidade Federal de Santa Maria, Brasil Walmir Albuquerque Barbosa, Universidade Federal do Amazonas, Brasil

\section{COMISSÃO EDITORIAL}

Cristiane Freitas Gutfreind, Pontifícia Universidade Católica do Rio Grande do Sul, Brasil Irene Machado, Universidade de São Paulo, Brasil

Eduardo Antonio de Jesus, Universidade Católica de Minas Gerais, Brasil

\section{CONSULTORES AD HOC}

Cleusa M. Andrade Scroferneker, Pontifícia Universidade Católica do Rio Grande do Sul, Brasil Francisco Rüdiger, Pontifícia Universidade Católica do Rio Grande do Sul, Brasil Juliana Freire Gutmann, Universidade Federal da Bahia, Brasil Karla Regina M. P. Patriota Bronsztein, Universidade Federal de Pernambuco, Brasil Laura Loguercio Cánepa, Universidade Anhembi Morumbi, Brasil Lucia Isaltina C. Leão, Pontifícia Universidade Católica de São Paulo, Brasil

\section{EQUIPE TÉCNICA}

\section{ASSISTENTE EDITORIAL I Márcio Zanetti Negrini}

REVISÃO DE TEXTOS I Press Revisão

EDITORAÇÃO ELETRÔNICA I Roka Estúdio

CONTATO I revistaecompos@gmail.com
COMPÓS I www.compos.org.br

Associação Nacional dos Programas de Pós-Graduação em Comunicação

Presidente

Edson Fernando Dalmonte

Programa de Pós-Graduação em Comunicação

e Cultura Contemporânea - UFBA

edsondalmonte@uol.com.br

Vice-presidente

Cristiane Freitas Gutfreind

Programa de Pós-Graduação em Comunicação Social - PUC-RS cristianefreitas@pucrs.br

Secretário-Geral

Rogério Ferraraz

Programa de Pós-Graduação em Comunicação

Universidade Anhembi Morumbi

rogerioferraraz@anhembimorumbi.edu.br 